\title{
KONSERVASI BAHASA BURU MELALUI PEMBELAJARAN MULOK BERKELANJUTAN DI KABUPATEN BURU
}

\author{
Varissca Utari Tuharea, Saidna Zulfiqar Bin-Tahir, Iin Sulastri Ode Ami, Abd \\ Rahman \\ Universitas Iqra Buru \\ Jl. Prof. Dr. Abdurrahman Basalamah, M.Si, Namlea, Maluku \\ E-mail: varisscatuharea135@gmail.com
}

\begin{abstract}
Abstrak:
Penomena miris tentang pergeseran bahasa daerah Buru saat ini merupakan faktor yang sangat dominan mengancam punahnya identitas masyarakatnya. Dari jumlah penduduk kabupaten Buru sebanyak 132.100 jiwa, hanya sekitar 14.000 yang mengetahui bahasa Buru dan hanya sekitar 5.000 masyarakat yang mampu dan aktif berkomunikasi menggunakan bahasa Buru. Penelitian ini bertujuan untuk mengkaji tentang kondisi bahasa-bahasa daerah di Indonesia khususnya di pulau Buru yang mengalami pergeseran yang berdampak pada kepunahan, apa saja faktor yang mempengaruhi kepunahan bahasa daerah Buru, dan bagamanakah langkah awal pencegahan kepunahan itu. Penelitian ini menggunakan pendekatan kualitatif dengan desain phenomenology untuk mendiskripsikan phenomena yang terjadi berkaitan dengan pergeseran bahasa daerah di pulau Buru. disimpulkan bahwa penomena language shift dan ancaman kepunahan bahasa Buru di kabupaten Buru semakin hari semakin meningkat jumlahnya disebabkan oleh dominasi bahasa Indonesia dan perkembangan teknologi informasi, dan kurangnya kesadaran masyarakat dan pemerintah dalam melestarikan bahasa daerah sebagai identitas mereka.
\end{abstract}

\section{A. Pendahuluan}

Indonesia merupakan salah satu negara yang dikenal sebagai negara yang memiliki beragam suku dan budaya. Keberagaman ini juga yang mengakibatnya adanya varian bahasa daerah yang ada di berbagai daerah di Indonesia (Hamied, 2012; Hoon, 2013). Hal inilah yang mengakibatkan Indonesia lebih unik dari negara-negara lainnya di dunia sebagai suatu kemajemukan identitas.

Bahasa merupakan identitas suatu bangsa, begitupun dengan Bahasa daerah yang ada di Indonesia (Wibawa, 2007). Walaupun sejatinya bahasa daerah bukanlah bahasa pemersatu bangsa, seperti halnya Bahasa Indonesia (Pengembangan, 2016). Tetapi, Bahasa daerah juga memegang peran penting yang sama seperti bahasa Indonesia itu sendiri (Primadesi, 2012; Pontoh, 2013). Misalnya, ketika kita berbicara dengan masyarakat dari suku adat maupun non 
suku adat lain di Indonesia. Untuk dapat berbicara dengan baik dan harmonis dengan mereka, kita dituntut untuk menguasai bahasa daerah yang mereka miliki sehingga pembicaraan itu akan mudah dimengerti dan timbul rasa percaya diri ketika sedang berkomunikasi dengan mereka dan juga makna dari pembicaraan yang dibicarakan dapat disampaikan dan dipahami dengan baik. Hal ini sesuai dengan definisi bahasa itu sendiri sebagai suatu sistem bunyi bermakna yang dipergunakan untuk komunikasi oleh kelompok masyarakat (Kridalaksana, 1985).

Sebagai alat komunikasi antar kelompok masyarakat, tentunya bahasa daerah itu juga memiliki peran penting sebagai identitas suatu kelompok masyarakat yang serba majemuk (Sudarsana, 2017). Identitas itulah yang sepatutnya dijaga dan dilestarikan agar bangsa itu terhindar dari misidentitats ataupun identity-shift mereka dengan identitas bangsa ataupun kelompok lain.

Berdasarkan data dari kemendikbud (2017), terdapat 11 bahasa dari 71 bahasa daerah yang telah dinyatakan telah punah. Kebanyakan kepunahan bahasa itu terjadi di daerah Papua. Kepunahan itu disebabkan oleh adanya pergeseran bahasa dan budaya dan modernisasi, terlebih lagi dengan perkembangan zaman era revolusi industry 4.0 yang begitu cepat, sehingga mengurangi penggunaan bahasa daerah dalam kehidupan sehari-hari dan berkurangnya jumlah dari penutur bahasa tersebut. Selain itu, dalam ethnologue: language of the world (2005) dikemukakan bahwa di Indonesia terdapat 742 bahasa, 737 bahasa diantaranya dinyatakan masih eksisatau masih digunakan oleh penuturnya. Sementara itu, terdapat dua bahasa yang berperan sebagai bahasa ibu (mother toungue). Sedangkan tiga bahasa lainnya telah punah. Beberapa diantara bahasa yang masih ada yang diprediksikan berada di ambang kehancuran atau terancam kepunahan disebabkan oleh berkurangnya penuturnya karena penutur aslinya hanya segelintir orang saja, tetapi ada juga yang dominan. Tak dapat pungkiri pula pula akan penyebab pengaruh bahasa Indonesia sebagai bahasa nasional dalam kehidupan sehari-hari terutama yang sering dipakai pada kegiatan resmi (formal) seperti pada sector pemerintahan dan pendididkan yang seringkali menyebabkan frekuensi pemakaian bahasa daerah semakin berkurang. Selain itu, kondisi masyarakat Indonesia yang multietnik dengan kemajemukan bahasa dan kebudayaan dapat berakibat pada pergeseran bahasa daerah. 
Kondisi masyarakat yang multietnik yang diikuti dengan terjadinya kontak antar etnik termasuk kontak bahasa dapat menyebabkan terjadinya berbagai fenomena kebahasaan, seperti bilingualisme atau bahkan multilingualisme dan interculturalism yang sering terjadi dalam kelompok bahasa minoritas (Bin Tahir, 2016 \& 2017). Kontak bahasa tersebut dapat pula mengakibatkan terjadinya penggeseran bahasa (language shift), bahkan kepunahan yakni perubahan secara tetap dalam pilihaan bahasa seseorang untuk keperluan komunikasi sehari-hari terutama sebagai akibat dari migrasi, akulturasi atau terjadinya perubahan bahasa (language change), yakni perubahan dalam bahasa sepanjang suatu periode (Kridalaksana, 1993).

Fenomena yang terjadi seperti yang telah diuraikan di atas menjadi alasan menarik untuk dikaji oleh para ahli bahasa, sebab fenomena tersebut bermuara pada kondisi kepunahan bahasa, karena pada dasarnya punahnya suatu bahasa tidak hanya berdampak pada dimensi kebahasaan tetapi juga berdampak pada dimensi kebudayaan masyarakat penutur bahasa (Tondo, 2009; Sobarna, 2010). Hal ini disebebkan karena melalui bahasa dapat diketahui cara pandang masyarakat tentang sesuatu dan melalui bahasa pula dapat diketahui aturan, tradisi, dan kepercayan sebuah kelompok etnik (Dixon, 1997).

Penomena miris tentang pergeseran bahasa daerah Buru saat ini merupakan faktor yang sangat dominan mengancam punahnya identitas masyarakatnya (BinTahir, 2016). Dari jumlah penduduk kabupaten Buru sebanyak 132.100 jiwa, hanya sekitar 14.000 yang mengetahui bahasa Buru dan hanya sekitar 5.000 masyarakat yang mampu dan aktif berkomunikasi menggunakan bahasa Buru (BPS-Buru, 2018). Hal itu tentunya disebabkan oleh berbagia faktor yang harus diinvestigasi dan diobservasi untuk mencaritemukan solusi yang tepat untuk melestarikan dan menonjolkan identitas dan asset budaya daerah.

Artikel ini mencoba mengkaji tentang kondisi bahasa-bahasa daerah di Indonesia khususnya di pulau Buru yang mengalami pergeseran yang berdampak pada kepunahan, apa saja faktor yang mempengaruhi kepunahan bahasa daerah Buru, dan bagamanakah langkah awal pencegahan kepunahan itu. Selain itu, artikel ini juga akan memberikan masukan kepada berberapa pihak terkait di 
Kabupaten Buru tentang bagaimana cara mengatasi kepunaahan bahasa daerah melalui nasionalisasi bahasa daerah itu sendiri, baik secara formal maupun nonformal dan informal melalui regulasi kebijakan dan pendidikan.

Berdasarkan latar belakang masalah yang telah diuraikan pada pendahuluan di atas, maka rumusan masalah artikel ini dapat dirumuskan sebagai berikut:

1. Bagaimanakah kondisi bahasa Buru yang ada di Kabupaten Buru?

2. Faktor-faktor apa sajakah yang mempengaruhi pergesera bahasa Buru di Kabupaten Buru?

3. Bagaimanakah strategi konservasi bahasa Buru dari ancaman kepunahan?

\section{B. Metode}

Artikel ini menggunakan pendekatan kualitatif dengan desain phenomenology untuk mendiskripsikan phenomena yang terjadi berkaitan dengan pergeseran bahasa daerah di pulau Buru. Objek kajian dalam artikel ini adalah masyarakat pulau Buru di kecamatan Namlea berjumlah 21 informan yang diobservasi dan diwawancarai dengan teknik purposive dengan kriteria bahwa partisipan yang diobservasi dan diwawancarai merupakan penduduk asli pulau Buru yang mengetahui dan menguasai bahasa Buru.

Instrumen yang digunakan dalam artikel ini adalah panduan observasi dan wawancara untuk menggali phenomena pergeseran bahasa daerah di kabupaten Buru yang terdiri dari domain penggunaan bahasa Buru dan penyebab kurangnya penggunaan bahasa Buru yang dapat mengancam bahasa Buru kepada kepunahan. Data yang dikumpulkan dianalisa menggunakan three-stage model yang terdiri dari penyajian data, reduksi, dan verifikasi atau penyimpulan dan dipresentasikan secara deskriptif.

\section{Hasil dan Pembahasan}

Bahasa adalah alat abstrak yang digunakan untuk berkomunikasi antar individu dengan individu, individu dengan kelompok, maupun kelompok dengan kelompok didalam suatu masyarakat. Bahasa menurut pengertiannya sendiri di dalam Undang-Undang No. 24 tahun 2009 bahwa Bahasa dan lambang negara 
merupakan sarana pemersatu, identitas dan wujud eksitensi bangsa yang menjadi simbol kedaulatan dan kehormatan negara sebagaimana diamanatkan dalam undang-undang dasar negara republikIndonesia tahun 1945. Selain itu, pengertian bahasa daerah di pertegas dalam pasal 1 ayat 5 Undang-Undang No 24 tahun 2009 bahwa bahasa daerah adalah bahasa yang digunakan secara turun-temurun oleh warga negara Indonesia di daearah-daearah dan di wilayah negara republik Indonesia.

Bahasa Buru sebagai bahasa daerah dan identitas masyarakat pulau Buru saat ini hanya sebatas simbol kedaerahan dan kebanggaan semata bagi penduduknya. Hal ini dibuktikan dengan berkurangnya penutur bahasa daerah Buru, yang mana dari jumlah populasi sebanyak 161.828 hanya terdapat 14.000 penutur bahasa Buru (Jayanti dkk, 2014). Pada saat mengobservasi dan mewancarai responden, peneliti tidak pernah mendengar salah satu dari responden ataupun responden dan penduduk di sekitaranya menggunakan bahasa daerah Buru. Hal ini dapat berakibat pada kepunahan bahasa daerah buru itu sendiri.

Berdasarkan hasil observasi terhadap kondisi bahasa daerah Buru dengan mengamati informan penggunanya dalam interaksi social sehari-hari, baik di rumah, lingkungan, sekolah/universitas, kantor, dan beberapa kondisi, maka dapat dipaparkan sebagai berikut:

Tabel 1: Kondisi Penggunaan Bahasa daerah Buru

\begin{tabular}{|c|c|c|c|c|}
\hline No & Domain & Selalu & Kadang & $\begin{array}{c}\text { Tdk } \\
\text { Pernah }\end{array}$ \\
\hline 1 & Penggunaan bahasa Buru di rumah & - & - & $\sqrt{ }$ \\
\hline 2 & $\begin{array}{l}\text { Penggunaan bahasa daerah Buru di } \\
\text { lingkungan }\end{array}$ & - & - & $\sqrt{ }$ \\
\hline 3 & $\begin{array}{l}\text { Penggunaan bahasa daerah Buru di } \\
\text { Sekolah/kampus }\end{array}$ & - & - & $\sqrt{ }$ \\
\hline 4 & $\begin{array}{l}\text { Penggunaan bahasa daerah Buru di } \\
\text { kantor }\end{array}$ & - & - & $\sqrt{ }$ \\
\hline 5 & $\begin{array}{l}\text { Penggunaan bahasa daerah Buru } \\
\text { saat kumpul keluarga }\end{array}$ & - & $\sqrt{ }$ & - \\
\hline 6 & $\begin{array}{l}\text { Penggunaan bahasa daerah Buru } \\
\text { pada acara resmi }\end{array}$ & - & $\sqrt{ }$ & - \\
\hline
\end{tabular}


Tabel di atas menunjukkan bahwa penggunaan bahasa Buru oleh ke 21 informan menunjukkan bahwa tidak pernah menggunakan bahasa Buru pada interaksi social, baik di lingkungan keluarga, sekolah/kampus, kantor, kecuali pada saat kumpul keluarga maupun acara-acara resmi saja. Hal ini menunjukkan minimnya penggunaan bahasa Buru dalam komunikasi sehari-hari yang dapat berdampak pada kepunahannya.

Kondisi saat ini menunjukkan bahwa bahasa daerah seakan-seakan dianaktirikan oleh penuturnya sendiri sehingga menyebebkan pergeseran bahasa daerah Buru kepada bahasa melayu-Ambon yang berdampak pada kepunahannya. Berdasarkan hasil wawancara dengan beberapa responden (ZW, ISO, TS, dan KT) menyatakan bahwa mereka lebih sering menggunakan bahasa Indonesia (baik resmi maupun Melayu-Ambon) dibandingkan dengan bahasa daerah yang ada disebabkan oleh adanya kemajuan teknologi melalui media online dan sinetron yang tertayang di TV, hal itulah yang menyebabkan mereka lebih cenderung untuk meniru dan mengikuti bahasa sinetron dalam pergaulan mereka sehari-hari ketimbang menggunakan bahasa mereka sendiri. Phenomena ini menyebabkan kealpaan penggunaan bahasa daerah yang begitu lama dan beresernya bahasa daerah Buru dengan bahasa lain.

Beberapa orang responden (YR, SZ, RB, AA, dan TS) menyatakan bahwa pergeseran bahasa daerah mereka disebabkan oleh dominasi penggunaan bahasa nasional yaitu bahasa Indonesia, baik di sekolah-sekolah, tempat pengajian, kampus, bahkan ketertarikan mereka pada dialog public dan politik yang ditayangkan pada TvOne dan MetroTV.

Hal ini sesuai dengan pendapat beberapa pakar yang lebih mempertegas akan faktor yang mempengaruhi pergeseran bahasa daerah. Kepunahan ini disebabkan oleh beberapa faktor yaitu:

1. Karena adanya interferensi bahasa yang terjadi dalam kurung waktu yang sangat lama mengakibatkan pergeseran bahasa dan kepunahan Bahasa (Widianto, 2015). 
2. Disebabkan oleh faktor politik. Kebijakan pemakaian bahasa nasional yang dulu dikenal sebagai politik bahasa nasional sedikit banyak juga berpengaruh terhadap keterpinggiran bahasa daerah (Budiono, 2009).

3. Bahasa daerah hanya digunakan sebagai bahasa pengantar pendidikan seperti yang tertera dalam undang-undang No 20, Tahun 2003, pasal 33 ayat 2 yaitu bahasa daerah dapat digunakan sebagai bahasa pengantar dalam tahap awal pendidikan apabila diperlukan dalam penyampaian pengetahuan dan/atau keterampilan tertentu.

4. Grimes (2000) mengemukakan bahwa gejalanya yaitu penurun secara drastis jumlah penutur aktif semakin berkurangnya ranah penggunaan bahasa, pengabaian dan pengenyahan bahasa ibu oleh penutur usia muda, usaha merawat identitas etnik tanpa bahasa ibu, penutur generasi terakhir sudah tidak cakap lagi menggunakan bahasa ibu, artinya tersisa penguasaan pasif (understanding without speaking), contoh-contoh mengenai semakin punahnya dialek-dialek satu bahasa kreol dan bahasa sandi.

5. Darwis (1985) menyatakan bahwa lingkungan pergaulan yang majemuk (suku). Medan tugas yang relative tidak tetap, dan orangtua berlainan suku.

Dari beberapa faktor yang telah disebutkan di atas, jika tidak diantisipasi dan segera dicaritemukan solusi maka akan berdampak pada kepunahan bahasa Buru secara berkesinambungan dan berdampak pada punahnya satu bahasa daerah di indonesia. Oleh karena itu, upaya yang harus dilakukan untuk mengatasinya adalah dengan meng-konservasikan bahasa Buru melalui pembelajaran Mulok di sekolah, institusi, dan perguruan tinggi. Upaya ini dilakukan dengan cara: 1) di pada bidang pendidikan, perlu adanya penambahan bahasa Buru sebagai mata pelajaran mulok di seluruh sekolah di kabupaten Buru, mulai dari tingkat TK, SD, SMP, SMA. Selain itu juga dapat ditambahkan dalam mata kuliah dasar umum di universitas yang ada di pulau Buru yakni Universitas Iqra Buru. 2) peran aktif orangtua dalam memperkenalkan bahasa daerah di dalam lingkungan keluarga melalui upaya pengenalan bahasa daerah sejak dini dalam konteks percakapan sehari-hari. 3) penutur bahasa daerah harus menjaga loyalitasnya dan identitas 
terhadap bahasa daerahnya. 4) memilih lingkugan pergaulan yang selalu produktif berbahasa daerah dengan aktif. 5) perlu adanya kesadaran masyarakat yang tinggi terhadap pentingnya berbahasa daerah sebagai upaya melestarikan budaya, dan 6) perlu adanya kabijakan pemerinta dalam merugulasi dan mengatur tentang pelestarian bahasa Buru pada segala sector, terutama pada bidang pendidikan formal, nonformal dan informal.

Upaya konservasi ini pada dasarnya memang tidak menjamin dapat menuntaskan masalah secara akurat terhadap permasalahan kepunahan bahasa daerah tersebut tetapi dengan adanya konservasi melalui pendidikan ini dapat mencegah kepunahannya, setidaknya secara berkesinambungan atas permasalah tersebut. Sehingga bahasa Buru di pulau Buru dapat terus dilestarikan dan lebih mendominasikan identitas masyarakat sebagai masyarakat yang berbudaya dan beridentitas.

\section{Simpulan}

Berdasarkan uraian di atas, dapat disimpulkan bahwa penomena language shift dan ancaman kepunahan bahasa Buru di kabupaten Buru semakin hari semakin meningkat jumlahnya disebabkan oleh dominasi bahasa Indonesia dan perkembangan teknologi informasi, dan kurangnya kesadaran masyarakat dan pemerintah dalam melestarikan bahasa daerah sebagai identitas mereka. Faktor yang telah diuraikan di atas dapat menjadi bahan acuan yang benar-benar harus diperhatikan dan dicaritemukan solusinya oleh pemerintah maupun masyarakat. Sebab bahasa daerah merupakan aset kultural masyarakat pulau Buru. Dengan adanya upaya konservasi bahasa Buru melalui pembelajaran Mulok di sekolahsekolah untuk mengatasi kepunahan bahasa daerah tersebut dan secara otomatis aset daerah akan tetap terjaga dan lestari.

Oleh karena itu, dapat direkomendasikan beberapa hal yaitu setiap individu masyarakat harus menyadari pentingnya pelestarian bahasa daerah sebagai aset kultural, mendorong generasi muda agar tetap loyal dan cinta bahasa daerah, peran aktif pemerintah untuk mensosialisasikan bahasa daerah sebagai wujud identitas peradaban daerah, keluarga sebagai wadah titik awal pelestarian bahasa daerah di dalam kehidupan anggota keluarga. Selain itu, dukungan pemerintah 
dalam merumuskan kebijakan ataupun Perda tentang pelestarian dan pemberdayaan bahasa Buru pada bidang pendidikan formal dan non-formal maupun social kemasyarakatan sebagai solusi pelestarian bahasa daerah sangatlah urgen untuk mengatasi pergesaran dan punahnya bahasa Buru.

\section{DAFTAR PUSTAKA}

Bin-Tahir, S. Z., \& Rinantanti, Y. (2016). Multilingual lecturers' competence in english teaching at the university of Iqra Buru, Indonesia. Asian EFL Journal, 5, 79-92.

Bin Tahir, S. Z. (2017). Multilingual teaching and learning at Pesantren Schools in Indonesia. Asian EFL Journal, 89, 74-94.

BPS-Buru. (2018). Geografi Kabupaten Buru. Online, diakses pada tanggal 21 Februari 2019 dari https://burukab.bps.go.id/subject/153/geografi.html\#subjekViewTab5.

Hendarman. (2013). Pemanfaatan Hasil Akreditasi dan Kredebilitas Asesor Sekolah/Madrasah. Jurnal Pendidikan dan Kebudayaan, Vol. 19(4), 532-542.

Aminah Suriaman, Saidna Zulfiqar Bin-Tahir, Sriati Usman.(2019). Designing WebBased English Listening Instruction: An Analysis of Indonesian University Student's Needs. Asian EFL Journl. Vol. 23(3.3), 28-40. https://www.asian-efljournal.com/11826/main-journals/2019-main-journal/volume-23-issue-3-3-2019/.

Kepmendikbud Nomor 193/P/2012 tentang Perubahan atas Kepmendikbud Nomor 174/P/2012 tentang Anggota Badan Akreditasi Nasional Perguruan Tinggi, Badan Akreditasi Nasional Sekolah/Madrasah, dan Badan Akreditasi Nasional Pendidikan Non Formal Periode Tahun 2012-2017.

Korten, D., and F. Alfonso. "1981." Bureaucracy and the Poor: Closing the Gap. Singapore: McGraw-Hill.

Aeni, N., Jabu, B., Rahman, M. A., Ismail, H., \& Bin-Tahir, S. Z. (2018). The Students' Needs in Maritime English Class at Ami Aipi Makassar, Indonesia. Journal of Language Teaching and Research, 9(6), 1284-1292.

Amri, M., Tahir, S. Z. A. B., \& Ahmad, S. (2017). The Implementation of Islamic Teaching in Multiculturalism Society: A Case Study at Pesantren Schools in Indonesia. Asian Social Science, 13(6), 125.

Amri, M., Afifuddin, A., \& Bin-Tahir, S. Z. (2018). Religious Pluralism of the Indonesian Traditional Islamic Education Institutions. The Journal of Social Sciences Research, 4(12), 446-450.

bin Tahir, S. Z. (2010). Modal Dasar Menguasai Bahasa Inggris: A Stepping Stone Toward Mastering English Grammar. Media Pustaka Qalam.

Bin Tahir, S. Z. (2015). The attitude of Santri and Ustadz toward multilingual education at Pesantren. International Journal of Language and Linguistics, 3(4), 210-216. 12.

Bin-Tahir, S. Z., \& Rinantanti, Y. (2016). Multilingual Lecturers' Competence in English Teaching at the University of Iqra Buru, Indonesia. Asian EFL Journal, 5, 7992.

Bin-Tahir, S. Z., Bugis, R., \& Tasiana, R. (2017). Intercultural Communication of a Multicultural Family in Buru Regency. Lingual: Journal of Language and Culture. 9(2). 8.

Bin Tahir, S. Z. (2017). Multilingual teaching and learning at Pesantren Schools in Indonesia. Asian EFL Journal, 89, 74-94. 
Bin-Tahir, S. Z., Saidah, U., Mufidah, N., \& Bugis, R. (2018). The Impact of Translanguaging Approach on Teaching Arabic Reading in a Multilingual Classroom. Ijaz Arabi Journal of Arabic Learning, 1(1).

Bin-Tahir, S. Z. (2010). English Teaching Methods at Pesantren IMMIM of Makassar. Jurnal Jupiter, 10(1). 34-43.

Bin-Tahir, S. Z. (2015). The Power of Love: The Role of Boyfriend in English Language Acquisition.

Bin-Tahir, S. Z., Atmowardoyo, H., Dollah, S., Rinantanti, Y., \& Suriaman, A. (2018). MULTILINGUAL AND MONO-MULTILINGUAL STUDENTS'PERFORMANCE IN ENGLISH SPEAKING. Journal of Advanced English Studies, 1(2), 32-38.

Bugis, R. (2018). SEATING ARRANGEMENT IN IMPROVING STUDENTSâ€TM SPEAKING SKILL AT IQRA BURU UNIVERSITY. Al-Lisan, 3(1), 79-92.

Hajar, I., Salija, K., \& Muliati, A. (2019). THE INTERFERENCE OF INDONESIAN ON THE STUDENTS'ENGLISH WRITING OF MUHAMMADIYAH UNIVERSITY OF MAKASSAR(Doctoral dissertation, UNIVERSITAS NEGERI MAKASSAR).

Harziko, H., Said, I. M., \& Darwis, K. (2018). FOLLOW THE EVENTS IN THE INDONESIAN LANGUAGE EXPRESSIVE SAID TRANSACTION IN THE TRADITIONAL MARKET TOWN OF BAUBAU. JURNAL ILMU BUDAYA, $6(1)$.

Irmawati, I. (2018). Kemampuan Menulis Puisi Bugis dengan Menggunakan Media Lingkungan Siswa Kelas VIII SMP Negeri 1 Tanasitolo Kabupaten Wajo (Doctoral dissertation, UNIVERSITAS NEGERI MAKASSAR).

Indrayani, N. (2018). Penggunaan campur kode dan alih kode dalam proses pembelajaran di smpn ubung pulau buru [the use of mixing code and switching code in learning process at smpn ubung buru island]. Totobuang, 5(2). 299-314.

Malik, S. (2014). Analisis faktor-faktor yang menentukan keputusan konsumen dalam pembelian motor scuter matic yamaha mio di jakarta barat. Analisis faktorfaktor yang menentukan keputusan konsumen dalam pembelian motor scuter matic yamaha mio di jakarta barat. UEU Digital Repository.

Magfirah, I. (2017). Efektivitas Model Pembelajaran Discovery dengan Setting Kooperatif Ditinjau dari Kemampuan Analogi dan Generalisasi Matematis Siswa Kelas VII MTs Al-Fakhriyah Makassar. Unpublish Thesis. Universitas Negeri Makassar.

Magfirah, I., Rahman, U., \& Sulasteri, S. (2015). PENGARUH KONSEP DIRI DAN KEBIASAAN BELAJAR TERHADAP HASIL BELAJAR MATEMATIKA SISWA KELAS VIII SMP NEGERI 6 BONTOMATENE KEPULAUAN SELAYAR. MaPan: Jurnal Matematika dan Pembelajaran, 3(1), 103-116.

Mufidah, N., Firdaus, U. Z., \& Tahir, S. Z. B. (2018). Model Pengayaan Tutor Bahasa: Studi pre-learning pada Shabahul Lughoh di Ma'had Sunan Ampel Al Aly. Jurnal At-Ta'dib Vol, 13(2).

Mufidah, N., Isyaty, I., Kholis, N., \& Tahir, S. Z. B. (2019). ICT FOR ARABIC LEARNING: A BLENDED LEARNING IN ISTIMA'II. $\square \square \square \square \square \square \square \square \square$ (LISANUNA): Jurnal Ilmu Bahasa Arab dan Pembelajarannya, 8(2), 174-183.

Masniati, A. (2011). The Analysis of Ellipsis in the Novel the Short Second Life of Bree Tanner by Stephenie Meyer (A Syntactic Approach) (Doctoral dissertation, Universitas Islam Negeri Alauddin Makassar).

Misnawati, M., Yusriadi, Y., Pengayoman, S. T. I. H., \& Bin-Tahir, S. Z. The Role of Family Hope Program Actor in Empowering Poor Society (Case Study of Bone Regency) Indonesia. 
Musyawir, M. (2017). Penyimpangan Prinsip Kesantunan Berbahasa dalam Interaksi Belajar-Mengajar Bahasa Indonesia Siswa Kelas XI SMA Negeri 2 Panca Rijang Sidenreng Rappang. Unpublish Thesis. Universitas Negeri Makassar.

Musyawir, M., \& Yulismayanti, Y. (2018). EFFECTIVENESS OF COOPERATIVE INTEGRATED READING AND COMPOSITION (CIRC) STRATEGIES IN WRITING ARGUMENTATION CORRECTIONS CLASS X SMA STATE 1 BUA PONRANG (KEEFEKTIFAN STRATEGI COOPERATIVE INTEGRATED READING AND COMPOSITION (CIRC) DALAM MENULIS KARANGAN ARGUMENTASI KELAS X SMA NEGERI 1 BUA PONRANG). Jurnal Gramatika: Jurnal Penelitian Pendidikan Bahasa dan Sastra Indonesia, 4(2), 416-427.

Nagauleng, A. M., Waris, A. M., \& Bi-Tahir, S. Z. (2018). Psycho pedagogical aspects of EFL learners' performance: a case study at IAIN of Manado. In PROCEEDINGS OF THE 65th TEFLIN INTERNATIONAL CONFERENCE (Vol. 65, No. 01).

Nirwana, A. R., \& Nirwana, A. R. (2018). Effects of Writing Corrective Feedback onStudents' Linguistic Error (Doctoral dissertation, UNIVERSITAS NEGERI MAKASSAR).

Rahman, A., Atmowardoyo, H., \& Salija, K. Podcast Effects on EFL Learners' Listening Comprehension. Learning, 97, 113.

Rasyid, M., Surachman, S., \& Sugiono, S. (2016). ANALISIS PERBAIKAN WORK STATION PADA PROSES PRODUKSI GARMENT DENGAN MENGGUNAKAN PENDEKATAN ENVIRONMENT ERGONOMIC. Journal of Engineering and Management in Industrial System, 4(2), 121-129.

RUSDI, M., \& RUSDI, M. (2017). Dinamika Sosial Masyarakat Di Sekiat Bukit Karampuang Desa Barugae Kecamatan Bulukumpa Kabupaten Bulukumba (Doctoral dissertation, Pascasarjana).

R Iye, S Susiati. (2018). NILAI EDUKATIF DALAM NOVEL SEBAIT CINTA DI BAWAH LANGIT KAIRO KARYA MAHMUD JAUHARI ALI (Educative Values in Sebait Cinta di Bawah Langit Kairo by Mahmud Jauhari Ali). Sirok Bastra, 6(2), 185-191. http://sirokbastra.kemdikbud.go.id/index.php/sirokbastra/article/view/135.

Salamun, T. (2018). DEIKSIS PERSONA BAHASA INDONESIA DIALEK AMBON [Personal Deixes of Indonesian Leanguage With Ambonese Dialect]. Totobuang, 5(2). 325-339.

S Susiati, R Iye. (2018). Kajian Geografi Bahasa dan Dialek di Sulawesi Tenggara: Analisis Dialektometri. Gramatika: Jurnal Ilmiah Kebahasaan dan Kesastraan. 6(2), $137-151$. http://gramatika.kemdikbud.go.id/index.php/gramatika/article/view/154.

Salamun, T. (2018). RELASI KEKERABATAN BAHASA HITU, WAKAL, MORELA, MAMALA, DAN HILA DI PROVINSI MALUKU [The Family Relationship Language Hitu, Wakal, Morela, Mamala, and Hila in Maluku Province]. TOTOBUANG, 6(1).

Saidna, Z., Tahir, B., Haryanto, A., Syarifuddin, D., \& Yulini, R. (2017). Multilingual Instructional Model of Pesantren Schools in Indonesia. Journal of Language Teaching and Research, 8(6), 1210-1216.

Saidna Zulfiqar Bin-Tahir, Aminah Suriaman, Yulini Rinantanti. (2019). Designing English Syllabus for Multilingual Students at Pesantren Schools. Asian EFL Journal. Vol. 23(3.3), 5-27. https://www.asian-efl-journal.com/11826/mainjournals/2019-main-journal/volume-23-issue-3-3-2019/.

Salikin, H., Bin-Tahir, S. Z., Supriono, H., \& Rahmawati, A. (2018). Students' Self and Group-Driven Motivation on Target-Oriented Activity in Grammar Learning. International Journal of English Linguistics, 8(5), 192. 
Salikin, H., \& Tahir, S. Z. B. (2017). The Social Media-Based Approach in Teaching Writing at Jember University, Indonesia. International Journal of English Linguistics, 7(3), 46.

Saidah, U., Bin-Tahir, S. Z., \& Mufidah, N. (2018). ARABIC TEACHERS'COMPETENCE: A CASE OF MADRASAH SCHOOLS IN MALUKU. Ijaz Arabi Journal of Arabic Learning, 1(2).

SZB Tahir, H Atmowardoyo, S Dollah. (2018). BELAJAR BERBICARA MULTIBAHASA UNTUK SANTRI PESANTREN. Yogyakarta, Deepublish. https://books.google.co.id/books?hl=en\&lr=\&id=b2WADwAAQBAJ\&oi=fnd \&pg=PR5\&dq=info:NRAwBySiHTcJ:scholar.google.com\&ots=uk2UoHVCXv \&sig=FmcbcN6AtoC3wuGIYTd9cPt0FE\&redir_esc $=\mathrm{y} \# \mathrm{v}=$ onepage $\& \mathrm{q} \& \mathrm{f}=$ false.

Tahir, B., \& Zulfiqar, S. (2015). Multilingual Behavior of Pesantren IMMIM Students in Makassar. Asian EFL Journal, 86, 45-64. Tahir, S. Z. A. B. (2017). Pengembangan Materi Multibahasa untuk Siswa Pesantren (Doctoral dissertation, Pascasarjana). Universitas Negeri Makassar.

Tahir, S. Z. B. (2015). Multilingual Teaching And Learning At Pesantren.14 Asian EFL Journal Conference.

Tahir, S. Z. B., \& Buru, D. U. I. (2012). Humor in "Bukan Empat Mata" Talk Show. Jurnal JUPITER, 5(4), 68-74.

TAHIR, S. Z. A. B. (2017). Pengembangan Materi Multibahasa untuk Siswa Pesantren (Doctoral dissertation, Pascasarjana).

Umar, A., Madani, M., Farida, U., Yusriadi, Y., Tamsa, H., Yahya, M., ... \& Sakkir, G. (2019). ONE-STOP SERVICE POLICY AS A BUREAUCRATIC REFORM IN INDONESIA. Academy of Strategic Management Journal, 18(2), 1-12.

Wahyuningsih, T., Bugis, M., \& Bin-Tahir, S. Z. (2019). Analysis of the Inequality on Inter-regional and Inter-time Income Distribution in Indonesia. The Journal of Social Sciences Research, 5(1), 1-8.

YULISMAYANTI, Y. (2017). KeefektifanStrategiCooperative Integrated Reading and Composition dalamPembelajaranMenulisKaranganArgumentasipadaSiswaKelas $X \quad$ SMA Negeri 1 BuaPonrangKabupatenLuwu (Doctoral dissertation, UNIVERSITAS NEGERI MAKASSAR).

A. Yusdianti Tenriawali. (2018). Representasi korban kekerasan dalam teks berita daring tribun timur: analisis wacana kritis [the representation victims of violence in tribun timur online news text: critical discourse analysis]. TOTOBUANG, 6(1), 1-15. http://totobuang.kemdikbud.go.id/jurnal/index.php/totobuang/article/view/71.

Susiati Susiati. (2018). Homonim bahasa kepulauan tukang besi dialek kaledupa di kabupaten wakatobi [the homonymon of tukang besi island languange in kaledupa dialect at wakatobi regency]. Totobuang, 6(1), 109-123. Http://totobuang.kemdikbud.go.id/jurnal/index.php/totobuang/article/view/72.

Risman Iye. (2018). Tuturan emosi mahasiswa kota baubau dalam ranah demonstrasi [emotional speech of the students in baubau city in the demonstration]. TOTOBUANG, 6(1), 125-138. Http://totobuang.kemdikbud.go.id/jurnal/index.php/totobuang/article/view/69.

Yusriadi, Y., Bin-Tahir, S. Z., Farida, U., Sakkir, G., \& Akbar, Z. (2019). Community Perception in the Use of" Songkok Recca" Hats based on Social Stratification. Anthropos: Jurnal Antropologi Sosial dan Budaya (Journal of Social and Cultural Anthropology), 5(1), 31-39.

Yulini Rinantanti, Saidna Zulfiqar Bin-Tahir, Aminah Suriaman. (2019). The Impact of EFL Senior High School Teachers' Performance in Papua, Indonesia toward the Students' English Learning Achievement. Asian EFL Journal. Vol. 23(3.3), 
431-447. https://www.asian-efl-journal.com/11826/main-journals/2019-mainjournal/volume-23-issue-3-3-2019/.

Asrifan, A. (2015). The use of pictures story in improving students' ability to write narrative composition. International Journal of Language and Linguistics, 3(4), 244-251. 